
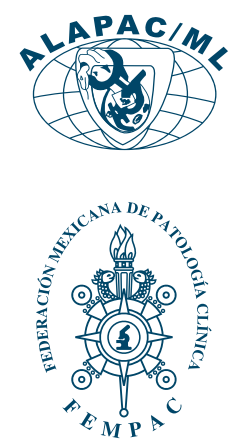

Artículo ORIginal

\title{
Ventajas e inconvenientes de 5 kits de detección de SARS-CoV-2 por RT-qPCR. Experiencia del laboratorio clínico del Hospital de Niños «Dr. Roberto del Río»
}

\author{
Advantages and disadvantages of 5 detection kits of \\ SARS-CoV-2 by RT-qPCR. Experience of the Hospital de \\ Niños «Dr. Roberto del Río» clinical laboratory
}

Ovalle Roberto,* Morales Pamela,* Clement Pascale, ${ }^{*, \ddagger}$ Rojas-Aedo Juan Francisco*

\begin{abstract}
Palabras clave: PCR, qPCR, RT-PCR kits de rendimiento, SARS-CoV-2.

Keywords: $P C R, q P C R$, performance kits $R T$ PCR, SARS-CoV-2.
\end{abstract}

* Laboratorio Clínico, Hospital de Niños «Dr. Roberto del Río», Santiago, Chile.

${ }^{\ddagger}$ Departamento de

Pediatría y Cirugía Infantil Norte, Facultad de Medicina, Universidad de Chile. Chile.

Correspondencia: Juan Francisco RojasAedo

E-mail: juan.

rojasaed@usach.cl

Recibido: 09 /09/ 2021 Aceptado: 05 /11/ 2021

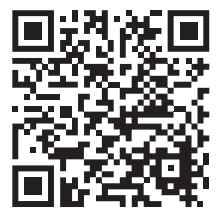

\section{RESUMEN}

Durante el año 2020, el laboratorio clínico del Hospital de Niños "Dr. Roberto del Río» realizó exámenes de detección de SARS-CoV-2 para diagnóstico clínico durante la pandemia; se trabajó con cinco kits de detección de distintos proveedores que mostraron tener diferencias en cuanto a sensibilidad, facilidad de trabajo, interpretación de resultados y presencia de falsos positivos. Después de usar al menos por 45 días cada kit, se observó que el kit LightCycler Multiplex RNA Virus Master con LightMix modular SARS-CoV-2 (COVID-19) RDRP y Modular Dx kit EAV Extraction Control (Roche) es el más conveniente de usar, ya que presenta las mejores características generales (tiempo de corrida, inhibición y facilidad de uso). En contraparte el kit menos conveniente fue el Allplex 2019-nCoVAssay (Seegene), por una alta tasa de inhibición y largo tiempo de corrida.

\section{ABSTRACT}

During 2020, the clinical laboratory of «Dr. Roberto del Río" Children's Hospital carried out detection tests for SARS-CoV-2 for clinical diagnosis during pandemics, with five different detection kits that showed differences in sensitivity, workflow, interpretation of results and presence of false positives. After using each kit for at least 45 days, the LightCycler Multiplex RNA Virus Master kit with LightMix modular SARS-CoV-2 (COVID-19) RdRp and Modular Dx kit EAV Extraction Control (Roche) was found to be the most convenient kits to use, presenting the best general performance (running time, workflow, and inhibition). In contrast, the less convenient kit was Allplex 2019-nCoV Assay (Seegene), due to a high inhibition rate and long running time.

\section{INTRODUCCIÓN}

D esde el inicio de la pandemia, en el año 2020, diversas empresas comenzaron a desarrollar y producir kits de detección del virus SARS-CoV-2 a gran velocidad, ${ }^{1}$ basándose en el conocimiento del virus que existía hasta ese momento. En nuestro país se adquirieron distintos kits, según disponibilidad, debido a la falta de importaciones, recurrentes quiebres de stock, producto del aumento explosivo de su uso a nivel mundial.
El laboratorio clínico del Hospital de Niños «Dr. Roberto del Río» volcó su área de biología molecular al servicio de la realización de exámenes de detección de SARS-CoV-2 para hospitales y consultorios de atención primaria de salud del área norte de la región metropolitana de Santiago de Chile, desde marzo de 2020 hasta la fecha. Entre marzo y noviembre de 2020 se trabajó con cinco kits de detección distintos que mostraron tener diferencias en cuanto a sensibilidad, facilidad de trabajo, interpretación de resultados y presencia de falsos positivos.

Citar como: Ovalle R, Morales P, Clement P, Rojas-Aedo JF. Ventajas e inconvenientes de 5 kits de detección de SARS-CoV-2 por RT-qPCR. Experiencia del laboratorio clínico del Hospital de Niños «Dr. Roberto del Río». Rev Mex Patol Clin Med Lab. 2021; 68 (2): 59-61. https://dx.doi.org/10.35366/103341 


\section{MATERIAL Y MÉTODOS}

Durante los primeros nueve meses de pandemia se utilizaron los siguientes kits y cada uno de ellos fue validado previamente de acuerdo con indicaciones entregadas por el Instituto de Salud Pública de Chile, laboratorio de referencia nacional: ${ }^{2}$

1. LightCycler Multiplex RNA Virus Master con LightMix modular SARS-CoV-2 (COVID-19) RDRP y Modular Dx kit EAV Extraction Control (Roche). ${ }^{3}$

2. SARS-CoV-2 Detection Kit for Research Use (Applied Biosystem-ThermoFisher). ${ }^{4}$

3. Real-Time Fluorescent RT-PCR Kit for Detecting SARS-COV-2 (BGI). ${ }^{5}$

4. SARS-CoV-2 Fluorescent PCR Kit (Maccura). ${ }^{6}$

5. Allplex 2019-nCoV Assay (Seegene). ${ }^{7}$

El desempeño de cada kit probado fue evaluado en comparación con el rendimiento basal del kit Allplex 2019-nCoV Assay de Seegene, validado al inicio de la pandemia por el Instituto de Salud Pública de Chile. ${ }^{2}$

Cada kit fue sometido a evaluación con muestras positivas de heterogéneos Cycle Threshold (CT) para evaluar la sensibilidad relativa. Posterior a su validación en sensibilidad, se usó por al menos 45 días en rutina y se logró establecer un porcentaje de inhibición en función de cuantas muestras se inhibían por cada 100 procesadas.
Por último, se compararon características como tiempo de corrida, tipo de control interno de extracción y número de genes objetivo. Con todo esto se estableció un puntaje comparativo que puede servir como referencia para la toma de decisiones a la hora de elegir un kit (Tabla 1).

\section{Elaboración del puntaje}

Para poder comparar, se realizó una ponderación en cada aspecto consensuada entre cuatro profesionales procesadores de muestras. Se consideró factor positivo o «a favor» una escala de 1 a 3, siendo 1 el menos favorable y 3 el óptimo (Tabla 2); además, se consideraron también aspectos negativos de cada kit como características «en contra», se utilizó en este caso ponderación negativa $(-1,-2,-3)$ en caso de ser un inconveniente menor se le asignaba un valor de $(-1)$, de importancia media (-2) o un inconveniente significativo (-3).

\section{RESULTADOS}

Gracias a esta ponderación o puntaje se definió al kit LightCycler Multiplex RNA Virus Master con LightMix modular SARS-CoV-2 (COVID-19) RDRP y Modular Dx Kit Eav Extraction Control (Roche) como el más conveniente de usar, con las mejores características generales, siendo óptimo en porcentaje de inhibición, tiempo de corrida, sensibilidad y facilidad en la interpretación de resultados.

\begin{tabular}{|c|c|c|c|c|}
\hline Kit & \% de inhibición & $\begin{array}{c}\text { Tiempo de } \\
\text { procesamiento }\end{array}$ & Característica a favor & Característica en contra \\
\hline Roche & $2-5$ & $60 \mathrm{~min}$ & $\begin{array}{l}\text { Robusto, no se inhibe } \\
\text { con facilidad }\end{array}$ & $\begin{array}{l}\text { Sensibilidad media, muestras con } \\
\text { baja carga viral no son identificadas }\end{array}$ \\
\hline $\begin{array}{l}\text { Applied } \\
\text { Biosystem }\end{array}$ & $2-5$ & $58 \mathrm{~min}$ & $\begin{array}{l}\text { Robusto, no se inhibe con } \\
\text { facilidad, incluye control } \\
\text { interno (detecta RNA humano) }\end{array}$ & $\begin{array}{l}\text { Cada gen se analiza por separado, por } \\
\text { lo que aumenta la cantidad de plásticos } \\
\text { y reacciones de PCR a realizar }\end{array}$ \\
\hline $\begin{array}{l}\text { Allplex } \\
\text { (Seegene) }\end{array}$ & $10-15$ & $1 \mathrm{~h} 50 \mathrm{~min}$ & $\begin{array}{l}\text { Reconoce } 3 \text { genes virales } \\
\text { (más sensible), no incluye } \\
\text { control interno en la mezcla }\end{array}$ & $\begin{array}{l}\text { Fácilmente se inhiben las reacciones } \\
\text { con interferentes en la muestra. Buffer } \\
\text { de muestra en mal estado aumenta } \\
\text { las inhibiciones a más de } 30 \%\end{array}$ \\
\hline $\mathrm{BGl}$ & $2-5$ & $1 \mathrm{~h} 15 \mathrm{~min}$ & $\begin{array}{l}\text { Sonda para ORF1ab muy } \\
\text { sensible, incluye control } \\
\text { interno (detecta RNA humano) }\end{array}$ & $\begin{array}{l}\text { Su alta sensibilidad entrega errores al azar } \\
\text { de acuerdo a lo indicado por el fabricante. } \\
\text { Esto induce al mayor número de muestras } \\
\text { dudosas que deben ser repetidas }\end{array}$ \\
\hline Maccura & $2-5$ & $1 \mathrm{~h} 20 \mathrm{~min}$ & $\begin{array}{l}\text { Reconoce } 3 \text { genes virales y } \\
\text { un control IC que se agrega } \\
\text { al momento de la extracción }\end{array}$ & $\begin{array}{l}\text { Baja sensibilidad en general. Detecta bien } \\
\text { muestras claramente positivas. Puede dejar } \\
\text { fuera muestras con carga viral más baja }\end{array}$ \\
\hline
\end{tabular}


Tabla 2: Resumen de puntaje en los kits evaluados.

\begin{tabular}{|c|c|c|c|c|c|}
\hline Kit & \% de inhibición & Tiempo de procesamiento & A favor & En contra & Total \\
\hline Roche & 3 & 3 & 3 & -1 & 8 \\
\hline Applied Biosystem & 3 & 3 & 3 & -2 & 7 \\
\hline Allplex (Seegene) & 2 & 1 & 3 & -2 & 4 \\
\hline BGI & 3 & 2 & 3 & -2 & 6 \\
\hline Maccura & 3 & 2 & 3 & -3 & 5 \\
\hline
\end{tabular}

En contraparte el kit menos ventajoso en nuestra experiencia fue Allplex 2019-nCoV Assay (Seegene), por su alta tasa de inhibición y largo tiempo de corrida, lo que afectaba la oportunidad de entrega de resultados en tiempos de alta demanda.

\section{DISCUSIÓN}

A pesar de lo difícil que ha sido enfrentar la pandemia en todos los niveles, en el área del laboratorio asistencial fue un reto, que se fue superando gracias a la seriedad de la investigación científica y al acelerado desarrollo de soluciones diagnósticas de laboratorio. En este último aspecto, el fuerte y rápido desarrollo de técnicas de detección nos sumió periódicamente en situaciones en las que era necesario evaluar de manera objetiva y sistemática las distintas herramientas de biología molecular disponibles. En esta línea, esta experiencia evidencia una estrategia de selección y evaluación de kits en función de las características estudiadas.

De acuerdo a las evaluaciones realizadas el kit de Roche fue el más idóneo de utilizar en la práctica debido a su alta especificidad, baja tasa de inhibición y rápido procesamiento de las muestras. Por otra parte, los kits de las marcas Maccura y BGI son kits de manejo sencillo para el operador, con baja complejidad en la preparación de las mezclas, lo que facilita la utilización de éstos; pero poseen una sensibilidad más baja que los kits de Roche y Applied Biosystem-ThermoFhiser, lo que es una desventaja a considerar en el uso de estos kits para el diagnóstico clínico.

Por último, el kit de Seegene, si bien la sensibilidad era comparable a Roche y Applied Biosystem-ThermoFhiser, cuenta con una tasa de inhibición considerablemente alta que implica repeticiones y falta a la oportunidad de entrega de resultados. Un ejemplo que afectó nuestra rutina de trabajo fue en momentos de uso de pool de muestras para optimizar el uso de reactivos. En este caso, que se inhibiera una muestra significaba repetir tres o más muestras, dependiendo de la estrategia de pooling.

En un laboratorio clínico es relevante hacer pruebas de performance de los kits a utilizar, sobre todo en el contexto de patógenos emergentes como ha sido el caso del SARS-CoV-2, ésto puede optimizar el flujo de trabajo y la oportunidad de entrega de resultados confiables al ámbito clínico.

\section{REFERENCIAS}

1. World Health Organization. Novel Coronavirus (2019-nCoV): Situation Report - 11. WHO; 2020.

2. Liotti FM, Menchinelli G, Marchetti S, Morandotti GA, Sanguinetti $M$, Posteraro $B$ et al. Evaluation of three commercial assays for SARS-CoV-2 molecular detection in upper respiratory tract samples. Eur J Clin Microbiol Infect Dis. 2021; 40 (2): 269-277.

3. Yip CCY, Sridhar S, Cheng AKW, Leung KH, Choi GKY, Chen JHK et al. Evaluation of the commercially available LightMix ${ }^{\circledR}$ Modular E-gene kit using clinical and proficiency testing specimens for SARSCoV-2 detection. J Clin Virol. 2020; 129: 104476.

4. Thermo Fisher Scientific. Research Solutions for SARS-CoV-2 (COVID-19). Thermo Fisher Scientific. Available in: https://www. thermofisher.com/search/results?query= Research\%20Solutions $\% 20$ for\%20SARS-CoV-2\%20(COVID-19)\&focusarea =Search\%20All

5. BGI. Real-Time Fluorescent RT-PCR Kit for Detecting SARS-CoV-2. US. BGI. 2021. Available in: https://www.bgi.com/us/sars-cov-2real-time-fluorescent-rt-pcr-kit-ivd/

6. Iglói Z, Leven M, Abou-Nouar ZAK, Weller B, Matheeussen V, Coppens J et al. Comparison of commercial realtime reverse transcription PCR assays for the detection of SARS-CoV-2. J Clin Virol. 2020; 129: 104510.

7. Farfour E, Lesprit P, Visseaux B, Pascreau T, Jolly E, Houhou N et al. The Allplex 2019-nCoV (Seegene) assay: which performances are for SARS-CoV-2 infection diagnosis? Eur J Clin Microbiol Infect Dis. 2020; 39: 1997-2000. 